\title{
I nvestigando laços afetivos com a escola a partir de mapas ambientais
}

\section{Exploring emotional bonds with school from environment maps}

\author{
Maíra Longhinotti Felippe* \\ Università degli Studi di Ferrara - UNIFE, Ferrara, Emília-Romanha, Itália
}

\section{Luana dos Santos Raymundo**}

Universidade Federal de Santa Catarina - UFSC, Florianópolis, Santa Catarina, Brasil

\section{Ariane Kuhnen***}

Universidade Federal de Santa Catarina - UFSC, Florianópolis, Santa Catarina, Brasil

\begin{abstract}
RESUMO
Este estudo investigou lugares na escola em que se gosta mais e menos de estar e as características físicas e psicossociais que os fazem mais ou menos preferidos segundo os participantes da pesquisa, 508 estudantes de uma escola pública de Santa Catarina. A investigação ocorreu por meio de um questionário contendo perguntas abertas e um mapa ilustrativo da escola. Entre os lugares mais preferidos para se estar destacaram-se os pátios, o ginásio poliesportivo e a cantina, sendo a possibilidade de execução de atividades agradáveis a justificativa mais recorrente para se gostar de um determinado ambiente. Já o refeitório, a sala de aula e a biblioteca foram os mais citados como menos preferidos, especialmente em razão de atributos físicos e sensações ambientais desagradáveis ali experienciados. A partir de uma maior compreensão das expectativas ambientais de adolescentes na escola, esperamos poder oferecer critérios para a concepção e a requalificação de ambientes escolares.
\end{abstract}

Palavras-chave: Ambiente escolar, Adolescência, Preferência ambiental, Psicologia ambiental.

\section{ABSTRACT}

The present study investigated places in a school where students most and least like to be by exploring the physical and psychosocial characteristics of those places that make them more or less preferred according to 508 students of a public school in Santa Catarina. The study was carried out by means of a questionnaire with open questions and an illustrative map of the school. The courts, the gymnasium and the canteen stood out among the most preferred places to be. Further, the most recurring reason to enjoy a particular environment was the possibility of executing enjoyable activities. The refectory, the classroom and the library were the most commonly cited as least favorite, especially because of unpleasant physical attributes and 
environmental sensations experienced there. Through a better understanding of the environmental expectations of adolescents in school, it is expected to offer criteria for the design and the requalification of school environments.

Keywords: School environment, Adolescence, Environmental preference, Environmental psychology

\section{I ntrodução}

Definir e qualificar a identidade pessoal, instaurar o sentido de pertencimento a um lugar e promover a apropriação e o cuidado ambientais são alguns dos papéis do comportamento de apego ao lugar, ou laços afetivos estabelecidos com lugares, apontados pela literatura (GIULIANI, 2004; PROSHANSKY; FABIAN; KAMINOFF, 1983; SPELLER, 2005). Cognições positivas em relação a um lugar como as traduzidas pela preferência ambiental - que refletem a existência de um ambiente físico com potencial de estabelecer certas funções e valores simbólicos, são consideradas preditoras de tais laços afetivos (GÜNTHER; NEPOMUCENO; SPEHAR; GÜNTHER, 2003; PROSHANSKY; FABIAN; KAMINOFF, 1983; SPELLER, 2005). O apego ao lugar, por sua vez, tem sido relacionado, entre outros, à conduta de cuidado ambiental (BONAIUTO; CARRUS; MARTORELLA; BONNES, 2002; BROWN; PERKINS; BROWN, 2004; BROWN; REED; HARRIS, 2002; BUIJS, 2009; HALPENNY, 2007; JORGENSEN; STEDMAN, 2006; RYAN, 2005; WALKER; RYAN, 2008): é quando o indivíduo passa a dirigir atenção ao lugar no sentido de garantir a manutenção de aspectos ambientais que satisfazem suas necessidades biopsicossociais e ratificam sua identidade pessoal.

A respeito da relação afetividade e cuidado na esfera ambiental, Walker e Ryan (2008) constataram, em uma pesquisa sobre a preferência por lugares da paisagem rural, forte correlação positiva desta com o engajamento para a conservação do ambiente. Em consonância a esse resultado, Halpenny (2007), ao examinar a relação entre apego ao lugar e intenções pró-ambientais, encontrou que o apego ao lugar foi positivamente relacionado a formas de intenção pró-ambiental em geral e em direção a locais específicos. Em outro estudo, Brown, Perkins e Brown (2004), que investigaram as relações entre incivilidades, atos criminais e apego ao lugar em vizinhanças, observaram que incivilidades e pouca vinculação afetiva com o lugar são importantes preditores de crime. Acreditaram que o apego desempenharia um papel no sentido de nutrir comportamentos e atitudes que protegem contra a violência, desencorajam a incivilidade e fortalecem laços sociais. Indivíduos mais apegados ao lugar seriam melhores guardiães de território, exibindo maior vigilância e protetividade. Além disso, tenderiam a cuidar mais do lugar, evitando atrair a violência que se dá em função da percepção 
de incivilidades, que favorecem atos criminais por transmitirem a imagem de que não se pode proteger o local.

Assim sendo, considerando a problemática do vandalismo em contextos escolares e partindo da hipótese de que características ambientais favoráveis à experiência de vinculação afetiva com o lugar são não só inibidoras de vandalismo, mas também promotoras do cuidado ambiental, propusemos um estudo que objetivou investigar os laços afetivos de estudantes com os diferentes ambientes de sua escola e os atributos físicos e psicossociais associados a esses ambientes. Esse estudo foi parte de uma investigação maior, cujo propósito foi identificar características físicas e psicossociais do ambiente de uma instituição escolar relacionadas ao comportamento de cuidado com a edificação (FELIPPE, 2010; FELIPPE; KUHNEN, 2011).

Apresentaremos aqui uma secção de pesquisa que utilizou como ferramenta investigativa o mapa da instituição escolar estudada, através do qual foi possível indagar acerca dos locais em que os estudantes mais e menos gostavam de estar ou ir. Consideramos um instrumento de pesquisa para além das técnicas tradicionais, que permitisse acessar percepções e representações por meio de linguagem diversa. O uso de imagens nas pesquisas psicológicas, embora não seja novo ${ }^{1}$, adverte para possibilidades metodológicas que estejam além das mensagens numéricas e escritas, tão comumente utilizadas nas ciências humanas.

A História e a Epistemologia da Psicologia revelam um debate constante acerca do delineamento metodológico mais adequado à construção do conhecimento. Para a Psicologia Ambiental, disciplina que estuda a influência recíproca entre o comportamento humano e seu ambiente físico-social, o holismo é um critério por vezes considerado nessa construção e diz respeito a uma postura sempre em busca de identificar a totalidade de fatores constituintes de uma situação em questão. Metodologicamente, esse critério se traduz por uma abordagem preocupada em capturar dados complementares, por meio de técnicas de pesquisa pertencentes a delineamentos metodológicos diferentes, que retratem o quadro geral em que estão inseridos o problema de pesquisa e seus atores. Evitam-se, assim, as lacunas e os vieses característicos das investigações que analisam dimensões parciais de um fenômeno.

Fotografias, mapas e desenhos, por exemplo, abrem novos campos de investigação para estudiosos da relação pessoa-ambiente e têm se mostrado efetivos, entre outros, por: (a) servirem à função de mediadores da realidade, quando a representam, já que tornam desnecessária a sua presença, ao tempo em que produzem um vínculo direto entre o observador e o conteúdo observado (JUSTO; VASCONCELOS, 2009); (b) ainda que possam ser utilizados com a simples função de ilustrar a realidade, suas contribuições mais 
importantes decorrem de sua capacidade de potencializar depoimentos para além da imagem observada, e comunicar as representações que os sujeitos pesquisados fazem do meio, promovendo a visibilidade de aspectos invisíveis por outros modos e a reflexão sobre si e sua relação com o ambiente (JUSTO; VASCONCELOS, 2009; MAURENTE; TITTONI, 2007); (c) seu uso independe da habilidade escrita ou verbal dos participantes, sendo especialmente importante para estudos que envolvem pessoas ou faixas etárias com maior dificuldade de expressão e, mesmo, compreensão (NEIVA-SILVA; KOLLER, 2002); (d) tais instrumentos tornam o processo investigativo divertido e atraente, tanto para o pesquisador, como para o pesquisado, ambos submetidos a uma realidade na qual elementos visuais desempenham um papel cada vez mais importante (LOIZOS, 2002).

Assim, descrevemos um processo de investigação psicológica a partir do uso da imagem, mais especificamente, de um mapa ambiental, utilizado com o escopo de investigar os laços afetivos que os estudantes possuíam com os diferentes ambientes da escola e os atributos físicos e psicossociais associados a estes. Esta etapa da pesquisa ofereceu dados que contribuíram, em um momento posterior de análise, para a identificação da relação apego ao lugar e cuidado ambiental, bem como para caracterizar atributos do ambiente associados a esses comportamentos.

\section{Método}

\subsection{Contexto de pesquisa}

A investigação ocorreu em uma escola pública estadual de educação básica, do Estado de Santa Catarina, que atende cerca de 5 mil estudantes. A escola, que completa em 2012, 120 anos de fundação, possui aproximadamente $22000 \mathrm{~m}^{2}$ de área construída em $34000 \mathrm{~m}^{2}$ de terreno. A heterogeneidade dos espaços ali observados definiu a escolha da instituição como contexto de pesquisa. Por suas dimensões, localização e por ser uma escola pública de referência no Estado de Santa Catarina, atende estudantes provenientes de contextos sociais, econômicos e étnicos diversificados, residentes tanto na região, como em cidades vizinhas.

A edificação foi concebida em dois pavimentos. Organiza-se, caracteristicamente, em uma sequência de prédios retilíneos e delgados, paralelos entre si, que se comunicam por meio de corredores transversais de passagem (ver Figura 1). Entre os prédios, dispõem-se pátios descobertos, onde se observam, com maior ou menor expressão, jardins gramados, canteiros, árvores e arbustos. A maior parte das salas de aula está situada no pavimento superior, 
onde se encontram também a oficina de reparos, a sala dos professores e salas de apoio pedagógico. O pavimento inferior é caracteristicamente dedicado aos setores administrativos e à oferta de serviços e atividades ao aluno e à comunidade escolar. É onde estão localizados refeitórios, cantinas, bibliotecas, espaços desportivos, auditórios e laboratórios de estudo.

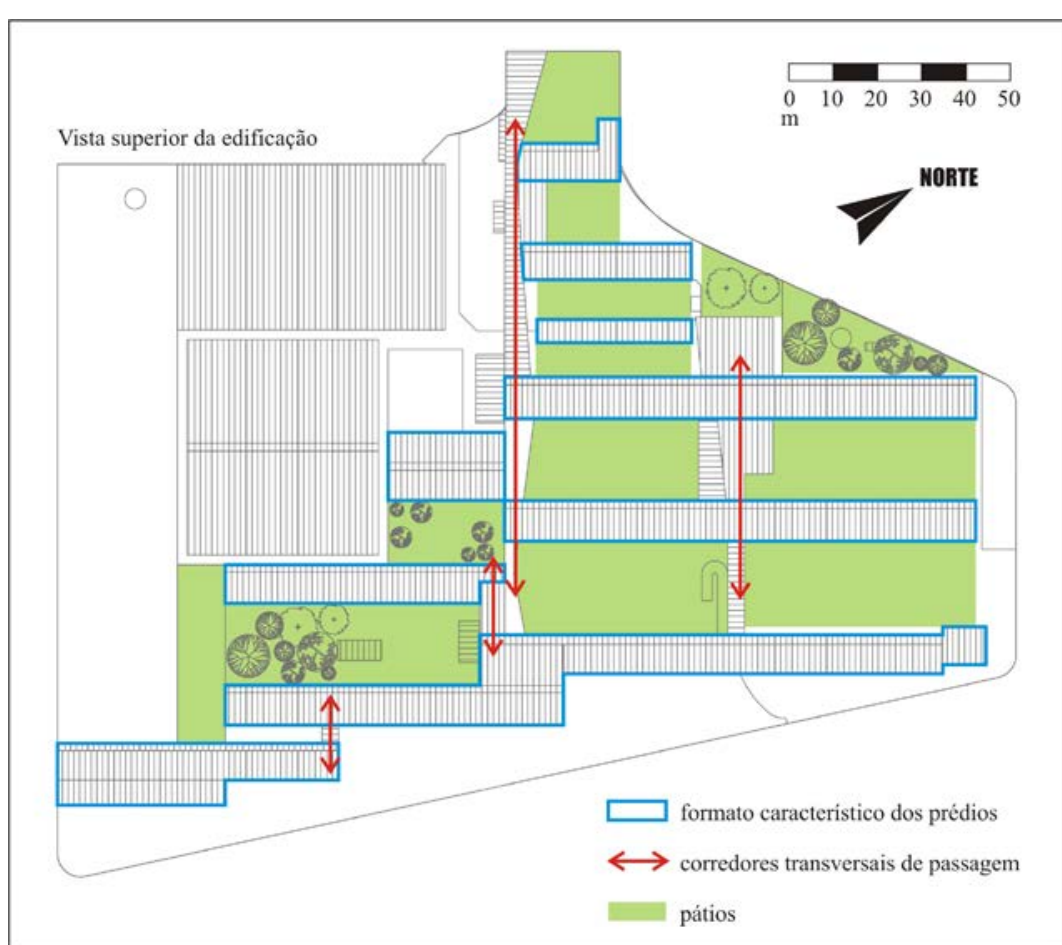

Figura 1. Esquema geral de organização da edificação escolar estudada.

\subsection{Participantes}

Participaram da pesquisa 508 estudantes, cursando da sétima série do ensino fundamental à terceira série do ensino médio, dos períodos matutino, vespertino e noturno. Essas séries compreendem a faixa etária apontada como tendo a maior participação em ações de depredação em escolas (GOLDSTEIN, 1996, 2004; TYGART, 1988; ZWEIG; DUCEY, 1978), tendo sido escolhidas, por esta razão, para a composição da amostra. Para a definição dos participantes, utilizamos a técnica de amostragem aleatória por conglomerados (BARBETTA, 2008). O erro amostral calculado com base em uma população de 2550 alunos - que cursavam as séries escolares em questão - foi de $3,97 \%$.

\subsection{I nstrumento}

A investigação maior da qual este relato faz parte ocorreu ao longo de duas etapas, compreendendo: (a) estudo preliminar por 
observação direta e avaliação do estado de conservação e das características de planejamento das instalações da escola, bem como análise de plantas arquitetônicas do local (Etapa 1); (b) administração de questionário auto-aplicável em situação coletiva e segunda observação direta do estado de conservação do prédio (Etapa 2). As duas etapas buscaram contemplar a investigação de diferentes dimensões da interação humano-ambiental, propondo técnicas centradas ora no ambiente, ora na pessoa, com vistas a atender aos objetivos da pesquisa.

O questionário administrado na Etapa 2 do estudo, composto de 11 questões, foi construído para a pesquisa, a partir das informações geradas pela Etapa 1, para ser auto-aplicado em situação coletiva de sala de aula. As questões presentes no instrumento investigaram características dos participantes, como data de nascimento, sexo e tempo de estudo na escola pesquisada; a prática de cuidado dos alunos e sua afetividade para com o lugar; bem como o que consideravam ser o melhor ambiente escolar.

Faz parte do estudo aqui relatado as perguntas do questionário para registro de idade e sexo do respondente, e um grupo de três questões no qual o estudante foi convidado a assinalar em um mapa da escola dois locais em que mais gostava de estar ou ir e dois locais em que menos gostava de estar ou ir, justificando cada escolha por meio da descrição do que existe ou acontece nesses ambientes. A consigna da primeira das três questões deste grupo foi: Este é um mapa da parte de baixo e de cima da sua escola. Escolha dois locais, no total, onde você mais goste de estar ou ir e faça um contorno ao redor de cada um deles. Os nomes que aparecem no desenho foram colocados para que você possa se localizar. Você pode contornar qualquer local, mesmo que seu nome não apareça no mapa. O mapa apresentado no questionário corresponde à imagem da Figura 2. 


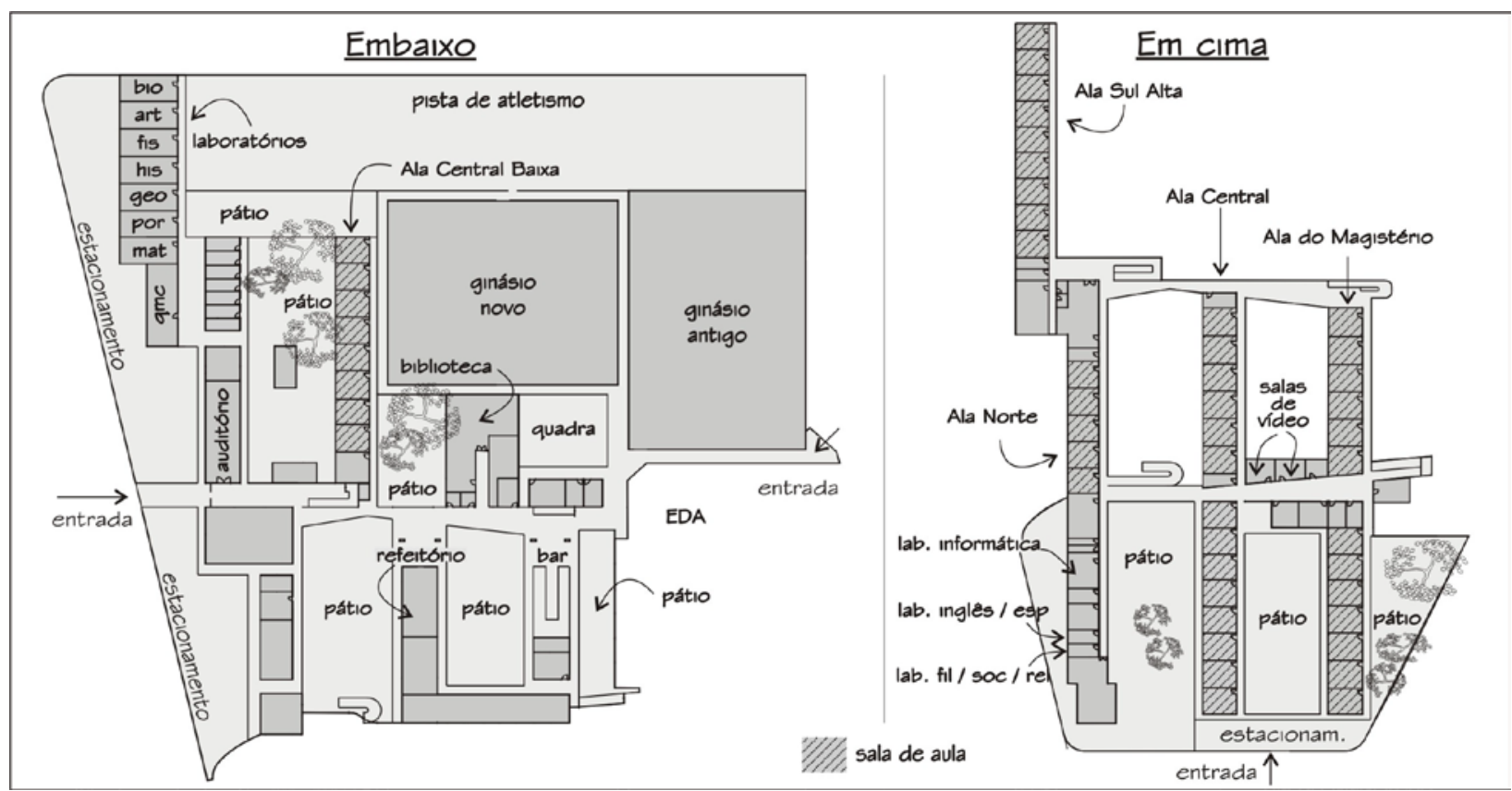

Figura 2. Mapa apresentado no questionário para a localização dos setores nos quais se gosta mais e menos de ir ou estar.

Em seguida, fizemos a seguinte solicitação: Escreva o nome dos locais que você contornou, por ordem de preferência, colocando o mais preferido em primeiro lugar. Escreva o que existe ou acontece nesses locais que faz com que você goste de ir ou estar lá. A última consigna no conjunto de três questões foi: Marque " $X$ " nos dois locais em que você menos gosta de estar ou ir (são duas marcações " $X$ " no total). Abaixo, escreva o nome dos locais, colocando aquele que você menos gosta em primeiro lugar. Escreva o que existe ou acontece nesses ambientes que faz com que você não goste de ir ou estar lá.

\subsection{Procedimentos}

Inicialmente, os setores da escola receberam uma denominação constituída por três letras e dois números (para códigos de letras, ver Tabela 1). As letras descrevem a classe a qual o setor pertence, por exemplo, classe de salas de aula (SAL), classe de banheiros (BAN), classe de pátios (PAT) e assim por diante. Os números, a sua vez, descrevem a ordem sequencial dos setores dentro de cada classe (e.g., SAL01, SAL02, SAL03, etc.). A Figura 3 indica a localização de cada setor no mapa da escola.

TABELA 1

Códigos de Letras Atribuídos aos Setores da Escola 
Maíra Longhinotti Felippe, Luana dos Santos Raymundo, Ariane Kuhnen Investigando laços afetivos com a escola a partir de mapas ambientais

\begin{tabular}{ll}
\hline Classe do setor & Código de letras \\
\hline 1. Auditório & AUD \\
\hline 2. Banheiro & BAN \\
\hline 3. Cantina & CAN \\
\hline 4. Biblioteca & BIB \\
\hline 5. Corredor & COR \\
\hline 6. Estacionamento & EST \\
\hline 7. Ginásio desportivo & GIN \\
\hline 8. Laboratório & LAB \\
\hline 9. Pátio & PAT \\
\hline 10. Quadra desportiva & QUA \\
\hline 11. Sala de aula & SAL \\
\hline 12. Sala de vídeo & SAV \\
\hline
\end{tabular}




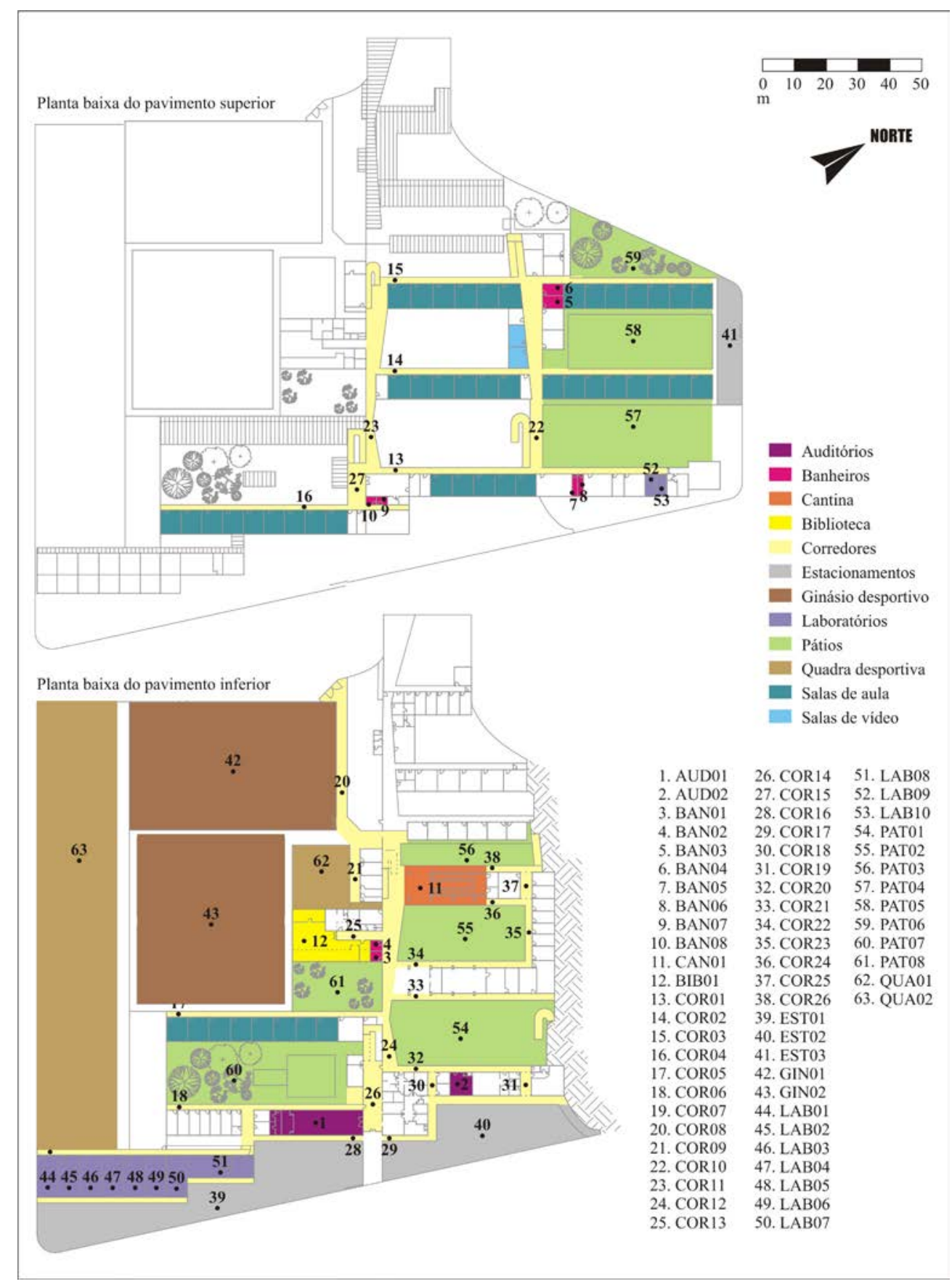

Figura 3. Localização dos setores da escola.

Após a codificação dos setores, realizamos um estudo piloto para a averiguação da qualidade do questionário em relação à linguagem utilizada, o formato das questões e o desenho do mapa da escola. Estudantes que cursavam da sétima série do ensino fundamental à terceira série do ensino médio foram então abordados em pátios da instituição, fora de seus horários de aula. Pelo menos três alunos de cada série responderam ao questionário piloto em cada uma das três fases em que foi testado. Sugestões de vocabulário e também orientação quanto ao formato das questões e à apresentação do 
mapa foram solicitadas aos estudantes e registradas pela primeira pesquisadora. Estas informações conduziram a duas reformulações do instrumento. Em relação ao mapa inicialmente proposto, as salas de aula passaram a ser identificadas e os nomes de mais setores foram incluídos, de modo a facilitar a localização dos ambientes por parte do estudante.

Após a realização do estudo piloto, foram sorteadas as turmas de alunos que participariam da pesquisa: ao todo, 30 turmas, 14 do período matutino, 13 do período vespertino e 3 do período noturno. Os questionários foram respondidos em sala de aula, individualmente, em um tempo máximo de 45 minutos, correspondente a uma hora-aula. Os estudantes receberam previamente uma breve orientação sobre o preenchimento das questões. Após a aplicação do instrumento, selecionamos de forma aleatória os participantes para a composição da amostra, respeitando-se a proporção entre séries escolares e períodos de estudo, matutino, vespertino e noturno.

\subsection{Análise dos Dados}

O tratamento dos dados coletados por meio das marcações realizadas sobre o mapa envolveu análise estatística descritiva, com o auxílio do pacote estatístico Statistical Package for Social Sciences - SPSS. As marcações realizadas pelos estudantes foram codificadas segundo o sistema de códigos de letras e números criado para a identificação dos setores da escola. As justificativas apresentadas nas questões, por sua vez, foram transcritas em meio digital e examinadas segundo análise de conteúdo temático-categorial, conforme organização proposta por Bardin (1977). Segundo a autora, esse tipo de análise prevê uma transformação dos dados brutos do corpus de respostas, "transformação esta que, por recorte, agregação e enumeração, permite atingir uma representação do conteúdo, ou da sua expressão, susceptível de esclarecer 0 analista acerca das características do texto" (BARDIN, 1977, p. 103).

Com esse objetivo, cada resposta discursiva foi codificada em unidades de registro denominadas elementos temáticos, que corresponderam a núcleos mínimos de significação levados em conta num processo posterior de enumeração (contagem) e categorização. Embora correspondências pudessem existir, o elemento temático, sendo de natureza semântica, não correspondeu necessariamente à palavra escrita, tomada em seu aspecto formal, mas à significação engendrada por ela.

Uma vez identificados os elementos temáticos de uma resposta, procedemos à contagem das unidades quanto à sua presença (registramos 1 para o elemento temático que compareceu na resposta) e à sua ocorrência (quantas vezes um mesmo elemento 
temático foi citado na resposta). Ao final, feito o somatório, tivemos para o corpus de análise o número de vezes que cada elemento esteve presente - servindo como indicador de quantos indivíduos da amostra fizeram (ou não) referência a ele - e o número total de vezes em que foi citado. Para Bardin (1977), tanto a presença como a ocorrência de um elemento podem ser significativos e correspondem, em certos casos, a uma medida de importância do tema para o grupo.

$\mathrm{Na}$ etapa seguinte da análise, os elementos temáticos foram agrupados, por semelhança, em categorias temáticas, ou classes de elementos de mesma natureza semântica, criadas a partir do material analisado, e nomeadas ao final do processo de categorização a fim de serem elucidativas para a pergunta geradora do corpus de respostas. Conforme expôs Bardin (1977, p. 119), a categorização na análise de conteúdo "tem como primeiro objectivo [...] fornecer, por condensação, uma representação simplificada dos dados brutos", partindo-se do pressuposto que "não introduz desvios [...] no material, mas que dá a conhecer índices invisíveis" . Por fim, ainda como parte de um processo progressivo de sistematização dos dados, as categorias temáticas foram agrupadas em grandes temas. Uma vez criadas as categorias e os temas, um juiz ${ }^{3}$ repetiu a classificação dos elementos temáticos a partir das categorias e temas propostos pelas pesquisadoras. O trabalho realizado pelo juiz possibilitou alterações no sistema de classificação criado, de modo que este se aproximasse dos princípios de categorização previstos por Bardin (1977): exclusão mútua, homogeneidade, pertinência, objetividade e fidelidade, e produtividade.

\section{Resultados}

\subsection{Caracterização da Amostra}

Dos 508 estudantes participantes da amostra, 57,4\% eram do sexo feminino. A média de idade foi de 15 anos e 7 meses (SD $=1$ ano e 6 meses), sendo a idade mínima de 12 anos e 3 meses e a máxima de 20 anos e 4 meses. Como é possível verificar na Figura 4, 168 alunos (33\%) frequentavam o Ensino Fundamental e 340 (67\%), o Ensino Médio, sendo $264(52 \%)$, do turno matutino, $215(42,3 \%)$ do vespertino e $29(5,7 \%)$ do noturno. 


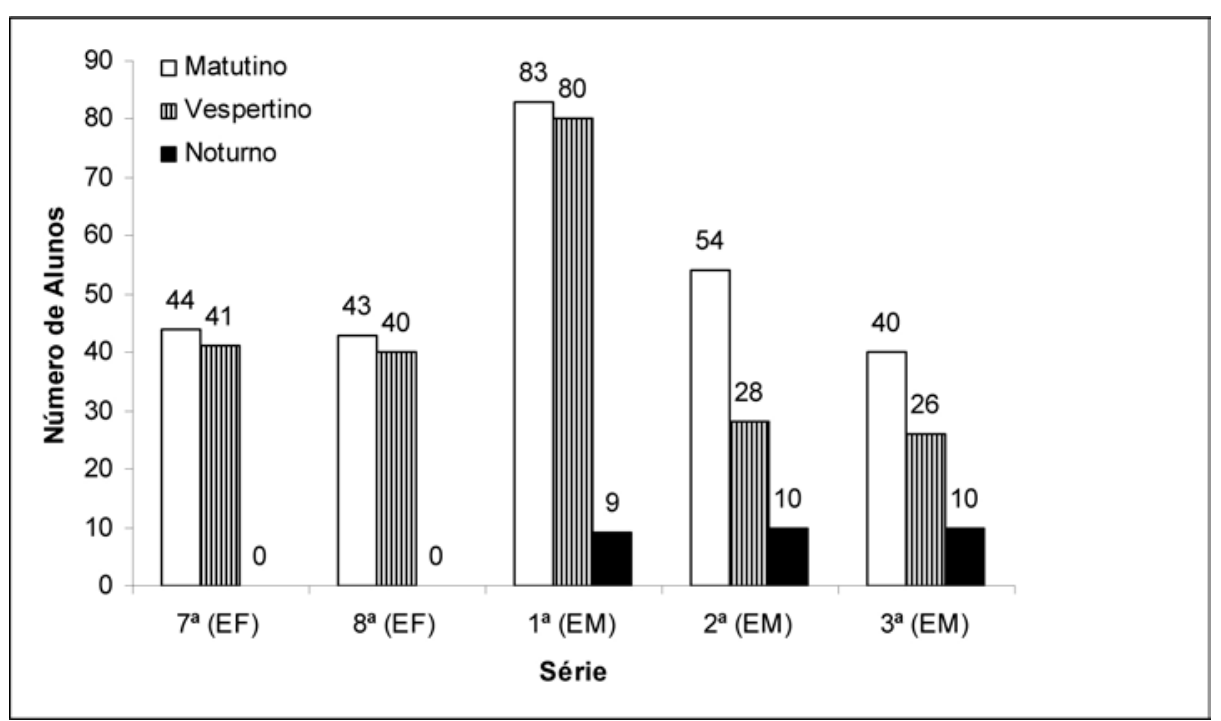

Figura 4. Número de alunos inquiridos por turno e série do Ensino Fundamental (EF) e Ensino Médio (EM).

\subsection{Lugares nos Quais Mais se Gosta de Estar ou I r}

$\mathrm{Na}$ questão em que os estudantes foram convidados a escolher dois locais em que mais gostavam de estar ou ir, apresentando-os por ordem de preferência, foram citados 51 setores diferentes para lugares mais preferidos $(\mathrm{N}=505)$ e 43 para lugares mais preferidos em segunda posição $(N=502)$. A Figura 5 apresenta os 10 lugares mais citados em cada um dos dois casos, abrangendo, respectivamente, $77 \%$ e $67,2 \%$ das citações ${ }^{4}$. A tabela com os dados completos de frequência de citação pode ser consultada em Felippe (2010).

Os setores mais citados como preferidos para estar ou ir em primeiro lugar, foram o Ginásio 2, o Pátio 1 e o Pátio 8, lembrados por 82 alunos $(16,2 \%), 62$ alunos $(12,3 \%)$ e 58 alunos (11,5\%), respectivamente. A estes se seguiram o Pátio $7(8,1 \%)$, a cantina $(6,9 \%)$, o Pátio $2(6,3 \%)$, a biblioteca $(5,1 \%)$, o Ginásio $1(5 \%)$, o Pátio $4(2,8 \%)$ e as salas de aula $(2,8 \%)$. Como mais preferidos em segundo lugar, destacaram-se o Ginásio 2, o Pátio 1, a cantina e o Pátio 2, com $59(11,8 \%)$ e 52 indicações $(10,4 \%)$ para os dois primeiros e 45 indicações (9\%) para cada um dos dois últimos. Seguiram-se a estes o Pátio $8(5,8 \%)$, as salas de vídeo $(5 \%)$, o Pátio $4(4,6 \%)$, o Pátio $7(4 \%)$, a biblioteca $(4 \%)$ e o Pátio $5(3,6 \%)$. É possível perceber que, dentre os 10 setores mais citados como preferidos em primeiro e em segundo lugar, 8 foram coincidentes, tendo o Ginásio 2 e Pátio 1 obtido o maior número de indicações em cada um dos dois casos. 


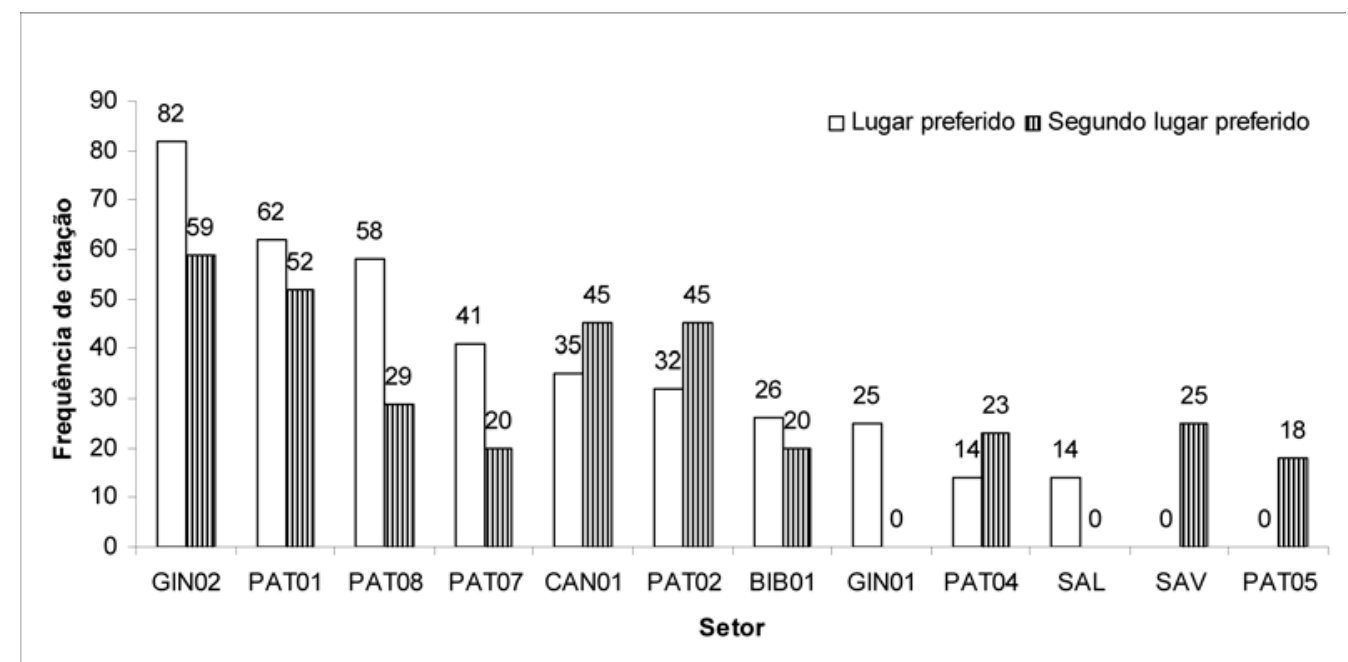

Figura 5. Lugares mais preferidos para estar ou ir em primeiro e segundo lugar.

A análise de conteúdo das justificativas para se gostar mais de estar no Ginásio 2 revelou 21 elementos temáticos em um total de 198 presenças e 201 ocorrências (ver Tabela 2). Os elementos temáticos mais presentes foram "praticar esporte", "atividade de diversão" e "atividade de descontração", indicados por 107 (75,89\%), 20 $(14,18 \%)$ e $19(13,47 \%)$ alunos, respectivamente, dentre os 141 respondentes. Juntos, estes elementos foram responsáveis por 148 ocorrências $(73,63 \%)$. A partir dos elementos temáticos, foi possível identificar 3 categorias diferentes no corpus de respostas. Estiveram presentes os temas do ambiente percebido e das atividades proporcionadas pelo lugar. Fazendo uso da categorização, foi possível inferir que os motivos para se gostar mais de estar no Ginásio 2 são: (a) a possibilidade de realizar atividades agradáveis $(83,58 \%$ das ocorrências), tais como praticar esporte, conversar com amigos, brincar, descontrair-se, extravasar e aprender; (b) a presença de atributos ambientais desejados $(10,45 \%$ das ocorrências), como limpeza, beleza, boa iluminação, organização, amplitude, proteção contra incidência direta do sol; e (c) sensações de bem-estar proporcionadas pelo lugar $(5,97 \%$ das ocorrências), como traduzem as expressões "sentir-se bem", "sentir-se à vontade", "sentir-se livre" e ter "boas lembranças".

TABELA 2

Elementos da Análise de Conteúdo Temático-Categorial das Justificativas para se Gostar Mais de Estar no Ginásio 2 


\begin{tabular}{|c|c|c|c|c|}
\hline Temas & $\begin{array}{l}\text { Categorias } \\
\text { temáticas }\end{array}$ & $\begin{array}{l}\text { Elementos } \\
\text { temáticos }\end{array}$ & Presenças & Ocorrências \\
\hline \multirow{15}{*}{$\begin{array}{l}\text { Ambiente } \\
\text { percebido }\end{array}$} & \multirow{10}{*}{$\begin{array}{l}\text { Atributos } \\
\text { ambientais } \\
\text { agradáveis }\end{array}$} & adequado & 6 & 6 \\
\hline & & amplo & 3 & 4 \\
\hline & & $\begin{array}{l}\text { bem } \\
\text { estruturado }\end{array}$ & 4 & 4 \\
\hline & & iluminado & 2 & 2 \\
\hline & & organizado & 1 & 1 \\
\hline & & protegido do sol & 1 & 1 \\
\hline & & limpo & 1 & 1 \\
\hline & & novo & 1 & 1 \\
\hline & & bonito & 1 & 1 \\
\hline & & Subtotal & 20 & 21 \\
\hline & \multirow{5}{*}{$\begin{array}{l}\text { Sensações } \\
\text { ambientais } \\
\text { agradáveis }\end{array}$} & $\begin{array}{l}\text { sentir-se à } \\
\text { vontade }\end{array}$ & 5 & 5 \\
\hline & & sentir-se bem & 5 & 5 \\
\hline & & $\begin{array}{l}\text { boas } \\
\text { lembranças }\end{array}$ & 1 & 1 \\
\hline & & sentir-se livre & 1 & 1 \\
\hline & & Subtotal & 12 & 12 \\
\hline \multirow{10}{*}{$\begin{array}{l}\text { Atividades } \\
\text { proporcionadas } \\
\text { pelo lugar }\end{array}$} & \multirow{10}{*}{$\begin{array}{l}\text { Possibilita } \\
\text { execução de } \\
\text { atividades } \\
\text { agradáveis }\end{array}$} & praticar esporte & 107 & 108 \\
\hline & & $\begin{array}{l}\text { atividade de } \\
\text { diversão }\end{array}$ & 20 & 21 \\
\hline & & $\begin{array}{l}\text { atividade de } \\
\text { descontração }\end{array}$ & 19 & 19 \\
\hline & & $\begin{array}{l}\text { conversar com } \\
\text { amigos }\end{array}$ & 7 & 7 \\
\hline & & interagir & 4 & 4 \\
\hline & & brincar & 3 & 3 \\
\hline & & $\begin{array}{l}\text { atividades para } \\
\text { extravasar }\end{array}$ & 3 & 3 \\
\hline & & aprender & 3 & 3 \\
\hline & & Subtotal & 166 & 168 \\
\hline & & Total & 198 & 201 \\
\hline
\end{tabular}

Quanto às justificativas para se gostar mais do Pátio 1 , segundo ambiente mais citado pelos estudantes, foi possível identificar 24 elementos temáticos em um total de 143 presenças e 149 ocorrências (ver Tabela 3). Os elementos temáticos mais presentes foram "conversar com amigos", "ver pessoas" e "sem barulho", o primeiro indicado por 54 alunos $(47,37 \%)$ e os dois últimos por 11 alunos cada um $(9,65 \%)$, dentre os 114 respondentes. Juntos, estes elementos foram responsáveis por mais da metade das ocorrências $(53,69 \%)$. Os mesmos temas e categorias temáticas identificados para o Ginásio 2 estiveram presentes neste conjunto de respostas, sendo possível inferir que os motivos para se gostar mais de estar no Pátio 1 são: (a) a oportunidade de realizar atividades agradáveis $(66,44 \%$ das ocorrências), tais como, conversar com amigos, divertir-se, descontrair-se, brincar, namorar, descansar e estar sozinho; (b) a presença de aspectos ambientais aprazíveis $(20,80 \%$ das 
ocorrências), como o silêncio, a arborização, a amplitude, a sombra, o sol, a boa circulação de ar e ter onde se sentar; (c) sensações como a de se sentir bem, à vontade e de ter boas lembranças $(12,75 \%$ das ocorrências).

TABELA 3

Elementos da Análise de Conteúdo Temático-Categorial das Justificativas para se Gostar Mais de Estar no Pátio 1

\begin{tabular}{|c|c|c|c|c|}
\hline Temas & $\begin{array}{l}\text { Categorias } \\
\text { temáticas }\end{array}$ & $\begin{array}{l}\text { Elementos } \\
\text { temáticos }\end{array}$ & Presenças & Ocorrências \\
\hline \multirow{14}{*}{$\begin{array}{l}\text { Ambiente } \\
\text { percebido }\end{array}$} & \multirow{10}{*}{$\begin{array}{l}\text { Atributos } \\
\text { ambientais } \\
\text { agradáveis }\end{array}$} & sem barulho & 11 & 13 \\
\hline & & ensolarado & 4 & 5 \\
\hline & & com bancos & 4 & 4 \\
\hline & & arborizado & 3 & 3 \\
\hline & & amplo & 2 & 2 \\
\hline & & arejado & 1 & 1 \\
\hline & & ao ar livre & 1 & 1 \\
\hline & & sombreado & 1 & 1 \\
\hline & & $\begin{array}{l}\text { sem muitas } \\
\text { pessoas }\end{array}$ & 1 & 1 \\
\hline & & Subtotal & 28 & 31 \\
\hline & \multirow{4}{*}{$\begin{array}{l}\text { Sensações } \\
\text { ambientais } \\
\text { agradáveis }\end{array}$} & $\begin{array}{l}\text { sentir-se à } \\
\text { vontade }\end{array}$ & 8 & 9 \\
\hline & & sentir-se bem & 8 & 8 \\
\hline & & $\begin{array}{l}\text { boas } \\
\text { lembranças }\end{array}$ & 2 & 2 \\
\hline & & Subtotal & 18 & 19 \\
\hline \multirow{14}{*}{$\begin{array}{l}\text { Atividades } \\
\text { proporcionadas } \\
\text { pelo lugar }\end{array}$} & \multirow{14}{*}{$\begin{array}{l}\text { Possibilita } \\
\text { execução de } \\
\text { atividades } \\
\text { agradáveis }\end{array}$} & $\begin{array}{l}\text { conversar com } \\
\text { amigos }\end{array}$ & 54 & 56 \\
\hline & & ver pessoas & 11 & 11 \\
\hline & & $\begin{array}{l}\text { atividade de } \\
\text { diversão }\end{array}$ & 9 & 9 \\
\hline & & $\begin{array}{l}\text { atividade de } \\
\text { descontração }\end{array}$ & 7 & 7 \\
\hline & & passar o recreio & 4 & 4 \\
\hline & & brincar & 2 & 2 \\
\hline & & namorar & 2 & 2 \\
\hline & & estar sozinho & 2 & 2 \\
\hline & & fazer lanche & 2 & 2 \\
\hline & & passar o tempo & 2 & 2 \\
\hline & & fazer fotocópias & 1 & 1 \\
\hline & & $\begin{array}{l}\text { atividade de } \\
\text { descansar }\end{array}$ & 1 & 1 \\
\hline & & Subtotal & 97 & 99 \\
\hline & & Total & 143 & 149 \\
\hline
\end{tabular}

A análise de conteúdo das justificativas para se gostar de estar nos demais lugares mais citados revelou a presença de temas e categorias temáticas bastante similares umas às outras. As tabelas com os elementos da análise completa podem ser consultadas em Felippe (2010). Além daquelas já apresentadas aqui, fez-se menção à 
qualidade do serviço oferecido no lugar, à sua boa localização, ao fato de ser adequado às necessidades do usuário, promover a interação social, a restauração de recursos psicofisiológicos e as atividades de aprendizagem.

\subsection{Lugares nos Quais Menos se Gosta de Estar ou I r}

$\mathrm{Na}$ questão seguinte, em que os estudantes foram convidados a escolher dois locais em que menos gostavam de estar ou ir, foram citados 65 setores diferentes para lugares menos preferidos $(\mathrm{N}=$ 492) e 64 para lugares menos preferidos em segunda posição ( $N=$ 466). A Figura 6 apresenta os 10 lugares mais citados em cada um dos dois casos, abrangendo, respectivamente, $50,6 \%$ e $49,7 \%$ das citações ${ }^{5}$. A tabela com os dados completos de frequência de citação pode ser consultada em Felippe (2010).

Os setores mais citados como menos preferidos para estar ou ir em primeiro lugar, foram o refeitório, as salas de aula, a biblioteca e o Ginásio 2. Os dois primeiros foram lembrados por 40 alunos $(8,1 \%)$ e 34 alunos $(6,9 \%)$, respectivamente. Os dois últimos por 29 alunos $(5,9 \%)$ cada um. A estes se seguiram a Quadra $2(5,1 \%)$, a cantina $(4,1 \%)$, os laboratórios $(3,9 \%)$, o Laboratório de Matemática - LAB07 $(3,7 \%)$, o Corredor $4 \mathrm{~A}(3,7 \%)$ e o Pátio 3 (3,3\%). Como menos preferidos em segundo lugar, destacaram-se o refeitório, a biblioteca e a Quadra 2, com $41(8,8 \%), 34(7,3 \%)$ e $26(5,6 \%)$ indicações, respectivamente. Seguiram-se a estes o Pátio $3(4,7 \%)$, as salas de aula $(4,5 \%)$, o Ginásio 2 (4,3\%), o Ginásio 1 (4,1\%), a cantina $(3,6 \%)$, as salas de vídeo $(3,4 \%)$ e a Escola de Aplicação $(3,4 \%)$. É possível perceber que, dentre os 10 setores mais citados como menos preferidos em primeiro e em segundo lugar, 7 foram coincidentes, tendo o refeitório obtido o maior número de indicações em cada um dos dois casos.

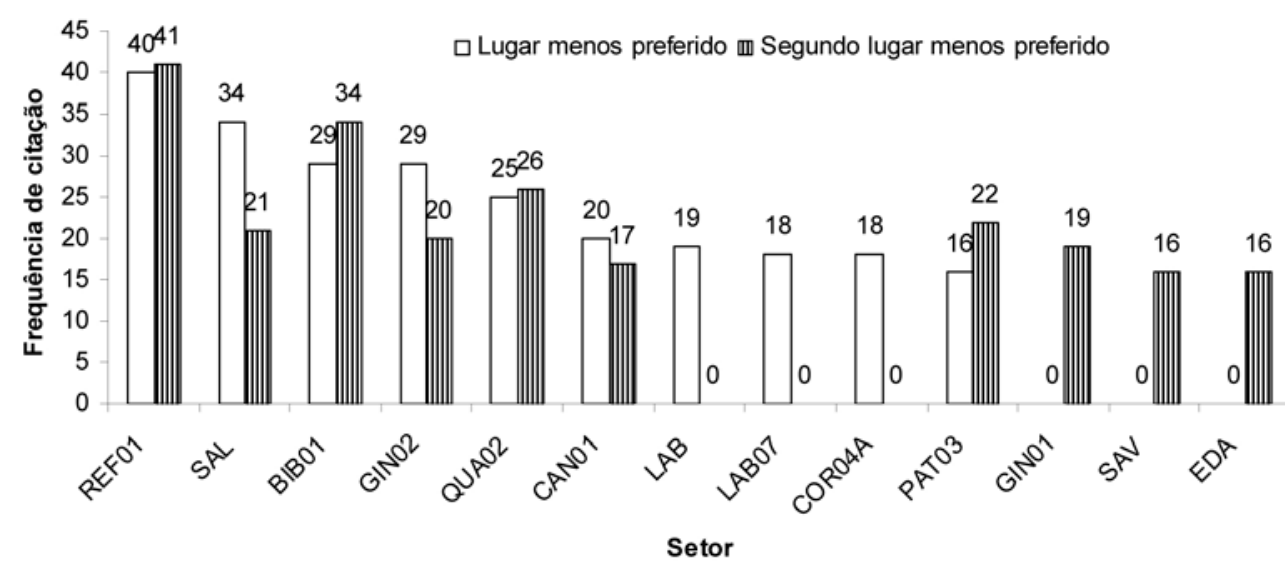


Figura 6. Lugares menos preferidos para estar ou ir em primeiro e segundo lugar.

A análise de conteúdo das justificativas para se gostar menos de estar no refeitório revelou 16 elementos temáticos em um total de 91 presenças e 91 ocorrências (ver Tabela 4). Os elementos temáticos mais presentes foram "pequeno", "alimentação ruim" e "impressão ruim", indicados por 21,15 e 12 alunos, respectivamente, dentre os 81 respondentes. Juntos, estes elementos foram responsáveis por 48 ocorrências. A partir dos elementos temáticos, foi possível identificar 3 categorias diferentes no corpus de análise. Estiveram presentes os temas da qualidade do ambiente físico e sensações e relacionados à função do lugar. Fazendo uso da categorização, foi possível inferir que os motivos para se gostar menos de estar no refeitório são: (a) serviço oferecido inadequado (44 ocorrências), em razão de alimentação deficiente, falta de higiene e atendimento desorganizado; (b) configuração ambiental e manutenção deficientes (27 ocorrências), uma vez que o ambiente é percebido como pequeno, mal conservado, mal ventilado, escorregadio e com acústica inadequada; (c) sensações ambientais desagradáveis (20 ocorrências), como traduzem as expressões "impressão ruim", "não se sentir à vontade", "não se sentir bem", "desconfortável" e "desinteressante".

TABELA 4

Elementos da Análise de Conteúdo Temático-Categorial das Justificativas para se Gostar Menos de Estar no Refeitório 


\begin{tabular}{|c|c|c|c|c|}
\hline Temas & $\begin{array}{l}\text { Categorias } \\
\text { temáticas }\end{array}$ & $\begin{array}{l}\text { Elementos } \\
\text { temáticos }\end{array}$ & Presenças & Ocorrências \\
\hline \multirow{12}{*}{$\begin{array}{l}\text { Qualidade do } \\
\text { ambiente físico } \\
\text { e sensações }\end{array}$} & \multirow{6}{*}{$\begin{array}{l}\text { Configuração } \\
\text { ambiental e } \\
\text { manutenção } \\
\text { inadequados }\end{array}$} & pequeno & 21 & 21 \\
\hline & & escorregadio & 2 & 2 \\
\hline & & $\begin{array}{l}\text { acústica } \\
\text { inadequada }\end{array}$ & 2 & 2 \\
\hline & & mal conservado & 1 & 1 \\
\hline & & mal ventilado & 1 & 1 \\
\hline & & Subtotal & 27 & 27 \\
\hline & \multirow{6}{*}{$\begin{array}{l}\text { Sensações } \\
\text { ambientais } \\
\text { desagradáveis }\end{array}$} & impressão ruim & 12 & 12 \\
\hline & & $\begin{array}{l}\text { não se sentir à } \\
\text { vontade }\end{array}$ & 3 & 3 \\
\hline & & desinteressante & 2 & 2 \\
\hline & & $\begin{array}{l}\text { não se sentir } \\
\text { bem }\end{array}$ & 2 & 2 \\
\hline & & desconfortável & 1 & 1 \\
\hline & & Subtotal & 20 & 20 \\
\hline \multirow[t]{8}{*}{ Função do lugar } & \multirow{8}{*}{$\begin{array}{l}\text { Serviço } \\
\text { oferecido } \\
\text { inadequado }\end{array}$} & $\begin{array}{l}\text { alimentação } \\
\text { ruim }\end{array}$ & 15 & 15 \\
\hline & & $\begin{array}{l}\text { serviço sem } \\
\text { higiene }\end{array}$ & 11 & 11 \\
\hline & & $\begin{array}{l}\text { serviço de } \\
\text { alimentação } \\
\text { com cheiro ruim }\end{array}$ & 10 & 10 \\
\hline & & $\begin{array}{l}\text { atendimento } \\
\text { ruim }\end{array}$ & 4 & 4 \\
\hline & & $\begin{array}{l}\text { atendimento } \\
\text { desorganizado }\end{array}$ & 3 & 3 \\
\hline & & $\begin{array}{l}\text { alimentação } \\
\text { deficiente }\end{array}$ & 1 & 1 \\
\hline & & Subtotal & 44 & 44 \\
\hline & & Total & 91 & 91 \\
\hline
\end{tabular}

Quanto às justificativas para se gostar menos da sala de aula segundo lugar mais citado como menos preferido - foi possível identificar 14 elementos temáticos em um total de 47 presenças e 47 ocorrências (ver Tabela 5). Os elementos temáticos mais presentes foram "atividades monótonas", "não gostar de estudar" e "tumultuado", indicados por 11, 8 e 6 alunos, respectivamente, dentre os 55 respondentes. Juntos, estes elementos foram responsáveis por mais da metade das ocorrências ( 25 ocorrências). A partir dos elementos temáticos, foram também identificadas 3 categorias diferentes no conjunto de respostas, pertencentes aos temas da qualidade do ambiente físico e sensações e da qualidade das interações sociais. A partir dos dados obtidos, foi então possível inferir que os motivos para se gostar menos de estar na sala de aula são: (a) as interações sociais próprias da sala de aula (35 ocorrências), representadas nas atividades monótonas, no ambiente 
tumultuado, nas provas, nas cobranças, no não poder se expressar, não gostar de estudar e não se identificar com as pessoas que frequentam o lugar; (b) a má conservação do ambiente (6 ocorrências); e (c) sensações ambientais desagradáveis (6 ocorrências), tais como não se sentir bem ou à vontade, e perceber 0 ambiente como sufocante.

TABELA 5

Elementos da Análise de Conteúdo Temático-Categorial das Justificativas para se Gostar Menos de Estar na Sala de Aula

\begin{tabular}{|c|c|c|c|c|}
\hline Temas & $\begin{array}{l}\text { Categorias } \\
\text { temáticas }\end{array}$ & $\begin{array}{l}\text { Elementos } \\
\text { temáticos }\end{array}$ & Presenças & Ocorrências \\
\hline \multirow{8}{*}{$\begin{array}{l}\text { Qualidade do } \\
\text { ambiente físico } \\
\text { e sensações }\end{array}$} & \multirow[t]{3}{*}{ Má conservação } & suja & 3 & 3 \\
\hline & & mal conservada & 3 & 3 \\
\hline & & Subtotal & 6 & 6 \\
\hline & \multirow{5}{*}{$\begin{array}{l}\text { Sensações } \\
\text { ambientais } \\
\text { desagradáveis }\end{array}$} & sufocante & 2 & 2 \\
\hline & & $\begin{array}{l}\text { não se sentir } \\
\text { bem }\end{array}$ & 2 & 2 \\
\hline & & $\begin{array}{l}\text { não se sentir à } \\
\text { vontade }\end{array}$ & 1 & 1 \\
\hline & & desagradável & 1 & 1 \\
\hline & & Subtotal & 6 & 6 \\
\hline \multirow{10}{*}{$\begin{array}{l}\text { Qualidade das } \\
\text { interações } \\
\text { sociais }\end{array}$} & \multirow{10}{*}{$\begin{array}{l}\text { Interações } \\
\text { sociais da sala } \\
\text { de aula }\end{array}$} & $\begin{array}{l}\text { atividades } \\
\text { monótonas }\end{array}$ & 11 & 11 \\
\hline & & $\begin{array}{l}\text { não gostar de } \\
\text { estudar }\end{array}$ & 8 & 8 \\
\hline & & tumultuado & 6 & 6 \\
\hline & & $\begin{array}{l}\text { não se } \\
\text { identificar com } \\
\text { as pessoas }\end{array}$ & 4 & 4 \\
\hline & & $\begin{array}{l}\text { não poder se } \\
\text { expressar }\end{array}$ & 2 & 2 \\
\hline & & $\begin{array}{l}\text { passar muito } \\
\text { tempo no lugar }\end{array}$ & 2 & 2 \\
\hline & & prova & 1 & 1 \\
\hline & & cobrança & 1 & 1 \\
\hline & & Subtotal & 35 & 35 \\
\hline & & Total & 47 & 47 \\
\hline
\end{tabular}

A análise de conteúdo das justificativas para se gostar menos de estar nos demais lugares mais citados também revelou a presença de temas e categorias temáticas similares entre si. As tabelas com os elementos da análise completa podem ser consultadas em Felippe (2010). Além das já apresentadas, foram mencionadas a ausência de identidade com o lugar, uma identificação negativa com o lugar, atributos ambientais não aprazíveis, tamanho e localização inadequados, uso que não faz parte do hábito, bem como procedimentos didáticos e administrativos que desagradam. 


\section{Discussão}

Com o propósito de investigar os laços afetivos de estudantes com os diferentes ambientes de sua escola, indagamos acerca dos locais em que mais e menos gostavam de estar ou ir, utilizando um mapa da instituição como estímulo de evocação das respostas. Dos 8 pátios existentes, 5 estiveram entre os 10 lugares mais preferidos e 6, entre os 10 lugares mais preferidos em segunda posição. Esse resultado coincidiu com os obtidos em outro momento da investigação maior da qual este relato faz parte, em que os pátios desta mesma escola obtiveram os maiores escores em uma escala de apego ao lugar (FELIPPE, 2010). O pátio escolar também tem sido apontado como um lugar favorito na memória de adultos (FERNANDES; ELALI, 2008). De acordo com Günther, Nepomoceno, Spehar, Günther (2003), a integração ao grupo de mesma faixa etária, o contato com o sexo oposto e a obtenção de autonomia são expectativas culturais da adolescência e tarefas para o desenvolvimento. Sendo assim, à semelhança do que discutiram os autores acerca da preferência de adolescentes por shoppings, é possível compreender que também a preferência por pátios na escola - um lugar onde os estudantes podem executar atividades diversas e flexíveis, e interagir com os colegas - é uma estratégia para a auto-regulação de seu desenvolvimento. Para Fedrizzi (2002) e Fernandes e Elali (2008), a importância do pátio escolar reside no fato de que este é um lugar privilegiado diante da redução progressiva das áreas de lazer nas cidades.

Quanto ao ambiente da sala de aula, biblioteca e laboratórios, observamos que todos foram lembrados pelos estudantes tanto como lugares nos quais se gosta mais de estar quanto como lugares nos quais se gosta menos de estar, mas para todos os casos, o número de citações foi maior na condição de lugar menos preferido, o que colocou a sala de aula e a biblioteca, por exemplo, entre os lugares menos preferidos para se estar, junto ao refeitório da escola. Este resultado provoca uma suposição: alguns ambientes da escola não são tão especiais ou privilegiados como se poderia imaginar e nem todos realmente gostam de lá estar ou sentem sua falta quando não estão presentes. Ao encontro dessa discussão, Günther, Nepomoceno, Spehar, Günther (2003) verificaram que a escola foi o segundo lugar indicado como menos preferido entre adolescentes do Distrito Federal e compareceu raramente entre aqueles ambientes nos quais se gostava de estar (na referida pesquisa, apenas 1,1\% dos respondentes informaram ser a escola o lugar preferido para estar, em oposição aos 35,3\% que escolherem a própria casa).

Ter contato frequente com o mesmo lugar dentro da escola - como a sala de aula, onde os alunos passam a maior parte do tempo - pode transformar a vivência espacial em uma rotina, por vezes, monótona 
e até desinteressante. Sommer (2002) percebeu que o grau de satisfação dos usuários de uma sala de aula diminuiu com o passar do tempo, ainda que o lugar tivesse sido muito bem avaliado em um primeiro momento, quando da sua renovação. Também as respostas dos estudantes ao questionário indicaram que a monotonia é uma razão para não se gostar de estar em um lugar, tornando-o menos preferido, tal como expressou o seguinte depoimento: "não gosto nem da ala, e não gosto da sala de aula, não por estar em mal estado, mas porque acho a sala de aula um local chato de estar mesmo, um tanto monótono demais" (D.C., 2010, M, 17) ${ }^{6}$. Em contrapartida, ambientes interessantes, com novidades e que despertam a atenção do usuário, correspondem a uma condição mais próxima da ideal, tal qual indicaram as seguintes respostas: "um lugar diferente, dinâmico, com professores bons e novidades" (D.C., 2010, F, 16) e um lugar "sempre com alguma coisa interessante e que desperta a curiosidade dos alunos" (D.C., 2010, F, 15). Por isso, ambientes de caráter incomum à rotina habitual da escola por vezes são percebidos como mais atraentes.

Um resultado inesperado ocorreu entre os espaços destinados à prática desportiva. O Ginásio 2 foi o mais citado como lugar preferido e também compareceu dentre os três primeiros lugares nos quais menos se gosta de estar. A maior parte das ocorrências de citações nas justificativas para se gostar menos deste ginásio (48 de 65 ocorrências) se referiu a atributos ambientais desagradáveis ali presentes, tais como, iluminação, ventilação e acústica deficientes, tamanho reduzido, ausência de banheiros e bancos. Em contrapartida, aqueles alunos que escolheram o Ginásio 2 como ambiente mais preferido não focalizaram sua atenção na estrutura física desse espaço, e sim nas atividades agradáveis proporcionadas pelo lugar (168 de 201 ocorrências). Por meio das justificativas apresentadas, é possível inferir que este ambiente possua qualidades de valor positivo e negativo bastante pronunciadas e que a preferência ou não pelo lugar dependa do equilíbrio ponderado entre estas qualidades, ou seja, dependa daquilo que é para o estudante mais ou menos importante.

A explicação dos resultados obtidos para a preferência em relação a um lugar pode estar na descrição dos processos de vinculação afetiva com os ambientes, identificados na literatura por Giuliani (2003, 2004): é provável que se apegar ou não a um determinado lugar da escola dependa do quanto as características físicas e psicossociais deste lugar resultem em (a) um julgamento positivo do mesmo frente à satisfação das necessidades do estudante e/ou (b) 0 estabelecimento de significados que correspondam a elementos relevantes de sua identidade.

É necessário apontar que a possibilidade de execução de atividades agradáveis esteve entre as justificativas mais recorrentes para se 
gostar de um determinado ambiente $(60,75 \%$ das ocorrências), junto a atributos físicos e sensações ambientais agradáveis (34,39\% das ocorrências) e bom relacionamento interpessoal (4,85\%). Enquanto que atributos físicos e sensações ambientais desagradáveis foram as razões mais citadas para não se gostar de estar em um lugar da escola $(56,40 \%$ das ocorrências), junto a atendimento ofertado deficiente (20,59\% das ocorrências), não se identificar com o lugar $(10,02 \%)$, procedimentos didáticos que desagradam $(7,24 \%)$ e usuários do lugar $(5,75 \%)$. Na mesma direção, em um estudo de Günther et al. (2003), adolescentes indicaram como não preferidos lugares que despertam sentimentos negativos.

Conforto ambiental e sensações ambientais agradáveis têm sido estudados pela Psicologia Ambiental dentro do tema de ambientes restauradores, em outras palavras, ambientes que restauram 0 indivíduo do estresse e da fadiga mental, especialmente presentes nos modos de vida urbanos. Baseados na Teoria da Restauração da Atenção (KAPLAN, 1995), estes estudos compreendem que o uso intenso e prolongado da atenção dirigida acarreta fadiga, perda de concentração e irritabilidade, colocando a pessoa em risco de estresse. Ambientes restauradores não exigem esforço da atenção e, por isso, permitem que a pessoa possa recuperar a capacidade de atenção perdida, circunstância acompanhada de sensações de bemestar (IVARSSON; HAGERHALL, 2008; KAPLAN, 2001; VAN DEN BERG; HARTIG; STAATS, 2007; VELARDE; FRY; TVEIT, 2007).

Conforme indicaram Van den Berg, Hartig e Staats (2007), embora as pesquisas demonstrem que pessoas tendem a perceber ambientes naturais como mais restauradores que ambientes construídos (BELL et. al., 2008; IVARSSON; HAGERHALL, 2008; VELARDE; FRY; TVEIT, 2007), tanto um quanto outro podem ter potencial de reparação, visto que este potencial é influenciado pelas necessidades, interesses e características pessoais, bem como pelas crenças sobre em que lugar a restauração pode ocorrer da melhor forma. A capacidade restauradora dos lugares também atua sobre a preferência ambiental (HIETANEN; KORPELA, 2004), ou seja, pessoas tendem a preferir lugares que possibilitam a restauração da atenção, como forma de garantir a satisfação de suas necessidades - o que explica, no contexto escolar, a preferência por pátios e ginásios esportivos, espaços que recuperam do esforço de atenção da sala de aula. Por essa razão, ambientes restauradores na escola, que promovam conforto, sensações agradáveis e identificação, também contribuem para a promoção de vínculos afetivos com o lugar, visto que um julgamento positivo deste frente à satisfação das necessidades da pessoa descreve um dos possíveis processos formadores de apego (GIULI ANI, 2003, 2004).

Quanto à identidade com lugares que dêem suporte ao uso e às relações sociais ocorridas no local e possibilitem a prática de 
atividades agradáveis, sabe-se de seu papel para a auto-regulação do desenvolvimento do adolescente (GÜNTHER; NEPOMUCENO ; SPEHAR; GÜNTHER, 2003). Também a qualidade satisfatória das interações sociais na escola e das propostas didático-pedagógicas têm sido apontadas pela literatura como importantes para a aproximação afetiva do estudante com o ambiente (ASTOR; MEYER; BEHRE, 1999; GOLDSTEIN, 2004; GUIMARÃES, 1985), o que explica a participação desses aspectos no conjunto de justificativas apresentadas pelos alunos.

\section{Considerações finais}

Este relato de pesquisa ilustrou uma investigação preocupada em conhecer relações de afetividade de estudantes com o seu ambiente escolar, utilizando para isso a técnica do questionário associada à apresentação de imagem, no caso, um mapa do ambiente em questão. Os dados coletados permitiram a identificação de setores da escola nos quais os alunos gostavam mais e menos de estar, bem como o conhecimento das características físicas e psicossociais desses ambientes que justificavam as escolhas realizadas pelos participantes.

Do ponto de vista metodológico, ressaltamos a contribuição representada pelo uso do mapa, efetivo para que diferentes setores da escola pudessem ser apropriadamente identificados e recuperados na memória de seus usuários. Na situação de aplicação coletiva de um questionário em sala de aula, era fundamental que os estudantes possuíssem em mãos uma imagem que representasse o ambiente investigado em sua totalidade e que lhes permitisse percorrer mentalmente todos os espaços a serem tomados em consideração. De outro modo, assumiríamos o risco de que determinados ambientes não fossem citados em razão de terem escapado à recordação dos estudantes no exato momento do preenchimento das questões. Além disso, a possibilidade de indicação gráfica do ambiente ao qual se fazia referência reduziu as chances de erro na identificação dos espaços por parte do pesquisador. Se a identificação dos ambientes nos quais se gostava mais e menos de estar tivesse ocorrido exclusivamente por meio da informação escrita, possivelmente um maior esforço para a decodificação dos dados teria sido necessário e maiores seriam as chances de equívocos.

Por fim, podemos sustentar que a contribuição prática do presente estudo reside no fato de oferecer parâmetros para a concepção, a manutenção e a requalificação do ambiente escolar, a partir de uma maior compreensão das expectativas e da identidade de lugar de adolescentes na escola. É necessário que tal compreensão seja por nós considerada como uma tecnologia de planejamento ambiental 
com vistas à sustentabilidade, na qual o equilíbrio das relações humano-ambientais possibilite uma continuidade qualificada, através do tempo, dos sistemas econômico, social e espacial nos quais estamos inseridos.

\section{Referências}

ASTOR, R. A.; MEYER, H. A.; BEHRE, W. J. Unowned places and times: Maps and interviews about violence in high schools. American Educational Research J ournal, Washington, v. 36, n. 1, p. 3-42, março $1999 . \quad$ Disponível em: <http://aer.sagepub.com/content/36/1/3.abstract>. Acesso em: 24 set. 2009.

BARBETTA, P. A. Estatística aplicada às ciências sociais. 7. ed. Florianópolis: UFSC, 2008.

BARDIN, L. Análise de conteúdo. Lisboa: Edições 70, 1977.

BELL, S.; HAMILTON, V.; MONTARZINO, A.; ROTHNIE, H.;TAVLOU, P.; ALVES, S. Greenspace and quality of life: A critical literature review. Stirling: Greenspace Scotland, 2008. 75 p. Disponível em: <http://www. openspace.eca.ac.uk/pdf/appendixf/OPENspacewebsite APPENDIX_F_resource_9.pdf $>$. Acesso em: 28 abr. 2010.

BONAIUTO, M.; CARRUS, G.; MARTORELLA, H.; BONNES, M. Local identity processes and environmental attitudes in land use changes: The case of natural protected areas. Journal of Economic Psychology, Philadelphia, v. 23, n. 5, p. 631-653, setembro 2002. Disponível em: <http://pdn.sciencedirect.com/science?_ob=Miamil mageURL\&_cid=2 $71667 \&$ user $=5674537 \&$ \& $\mathrm{pii}=\mathrm{S} 0167487002001216 \&$ \& check $=\overline{\mathrm{y}} \boldsymbol{\varepsilon}$ _origi $\mathrm{n}=$ articlē\&_zone $=$ toolbar $\bar{\varepsilon} \_$coverDate $=31$-Oct-

$2002 \&$ view $=c \&$ originContentFamily $=$ serial $\&$ wchp $=$ dGLbVItzSkWb\&md5=4981781b87c0f831171beccc2d88a122/1-s2.0S0167487002001216-main.pdf>. Acesso em: 23 set. 2009.

BROWN, B. B.; PERKINS, D. D.; BROWN, G. Incivilities, place attachment and crime: Block and individual effects. Journal of Environmental Psychology, Philadelphia, v. 24, n. 3, p. 359-371, 2004.

em:

<http://www.observatoriodeseguranca.org/files/sdarticle.pdf>.

Acesso em: 23 set. 2009.

BROWN, G. G.; REED, P.; HARRIS, C. C. Testing a place-based theory for environmental evaluation: An Alaska case study. Applied Geography, Philadelphia,v. 22, n. 1, p. 49-76, janeiro 2002. Disponível em: <http://www.cnrhome. uidaho.edu/documents/brown\% 20appld\% $20 \mathrm{~g}$ eog\% 2002. pdf? pid=104280\&doc $=1>$. Acesso em: 23 set. 2009. 
BUIJS, A. E. Public support for river restoration: A mixed-method study into local residents' support for and framing of river management and ecological restoration in the Dutch floodplains. J ournal of Environmental Management, Philadelphia, v. 90, n. 8, p. 2680-2689, 2009. Disponível em: <http://pdn.sciencedirect.com/science?_ob=Miamil mageURL\&_cid=2 $72592 \&_{-}$user $=5674537 \&_{\_}$pii $=\mathrm{S} 0301479709000541 \&_{-}$check $=\overline{\mathrm{y}} \&_{\text {_ }}$ origi $\mathrm{n}=$ article $\varepsilon_{-}$zone $=$toolbar $\bar{\varepsilon} \_$coverDate $=30$-J un$2009 \&$ view $=c \&$ originContentFamily $=$ serial $\& w c h p=d G L z V I B-$ zSkzV\&md5=dbbcbc0add386cb26b95150d01c92b4d/1-s2.0S0301479709000541-main.pdf>. Acesso em: 23 set. 2009. FEDRIZZI, B. A organização espacial em pátios escolares grandes e pequenos. In: RIO, V. D.; DUARTE, C. R.; RHEINGANTZ, P. A. (Orgs.). Projeto do lugar: colaboração entre psicologia, arquitetura e urbanismo. Rio de Janeiro: Contra Capa/PROARQ, 2002, p. 221229.

FELIPPE, M. L. Contribuições do ambiente físico e psicossocial da escola para o cuidado com a edificação. 2010. $121 \mathrm{f}$. Dissertação (Mestrado em Psicologia) - Departamento de Psicologia, Universidade Federal de Santa Catarina, Florianópolis. 2010. Disponível em: <http://www.cfh.ufsc. br/ ppgp/Maira\% 20Longhinotti\% 20Felippe.pdf >. Acesso em: 02 abr. 2011.

FELIPPE, M. L.; KUHNEN, A. Contribuições do ambiente físico e psicossocial da escola para o cuidado com a edificação. In: VILLODRES, M. C. H.; FERNÁNDEZ-RAMÍREZ, B.; MÉNDEZ, M. J. M.; FERRER, C. M. S. (Orgs.). Espacios urbanos y sostenibilidad: claves para la ciencia y la gestión ambiental. Almería: Editorial Universidad de Almería, 2011, p. 258-267.

FERNANDES, O. S; ELALI, G. A. Reflexões sobre o comportamento infantil em um pátio escolar: $O$ que aprendemos observando as atividades das crianças. Paidéia, Ribeirão Preto, v. 18, n. 39, p. 4152, $2008 . \quad$ Disponível em: <http://www.scielo.br/pdf/paideia/v18n39/v18n39a05.pdf>. Acesso em: 23 set. 2009.

GIULIANI, M. V. Theory of attachment and place attachment. In: BONNES, M.; LEE, T.; BONAIUTO, M. (Orgs.). Psychological theories for environmental issues. Aldershot: Ashgate, 2003, p. 137-170.

O lugar do apego nas relações pessoas-ambiente. In: TAASSTARA, E. T. O.; RABINOVICH, E. P.; GUEDES, M. C. (Orgs.). Psicologia e ambiente. São Paulo: Educ, 2004, p. 89-106.

GOLDSTEIN, A. P. The psychology of vandalism. New York: Plenum Press, 1996. 
GOLDSTEIN, A. P. Controlling vandalism. In: CONOLEY, J. C.; GOLDSTEIN, A. P. (Orgs.). School violence intervention: a practical handbook. 2. ed. New York: Guilford, 2004, p. 324- 358.

GUIMARÃES, A. M. Vigilância, punição e depredação escolar. Campinas: Papirus, 1985.

GÜNTHER, I. A.; NEPOMUCENO, G. M.; SPEHAR, M. C.; GÜNTHER, H. Lugares favoritos de adolescentes no Distrito Federal. Estudos de Psicologia, Natal, v. 8, n. 2, p. 299-308, mai./ago. 2003. Disponível em: <http://www.scielo.br/pdf/epsic/v8n2/19046.pdf>. Acesso em: 30 abr. 2009.

HALPENNY, E. Examining the relationship of place attachment with pro-environmental intentions. In: 2006 NORTHEASTERN RECREATION RESEARCH SYMPOSIUM, 2006, Bolton Landing, NY. Proceedings of the 2006 Northeastern Recreation Research Symposium, Bolton Landing, NY, U.S. Forest Service, Northern Research Station, 2007, p. 63-66. Disponível em: <http://www.treesearch.fs.fed.us/pubs/12655>. Acesso em: 24 set. 2009.

HIETANEN, J. K.; KORPELA, K. M. Do both negative and positive environmental scenes elicit rapid affective processing? Environment and Behavior, Thousand Oaks, CA, v. 36, n. 4, p. 558-577, julho 2004. Disponível

em: <http://eab.sagepub.com/content/36/4/558.abstract>. Acesso em: 25 jul. 2009.

IVARSSON, C. T.; HAGERHALL, C. M. The perceived restorativeness of gardens: Assessing the restorativeness of a mixed built and natural scene type. Urban Forestry \& Urban Greening, Philadelphia, v. 7, n. 2, p. 107-118, maio 2008. Disponível em: <http://pdn.sciencedirect.com/science?_ob=Miamil mageURL\&_cid=2 $73184 \&_{-}$user $=5674537 \&_{\text {_ }} \mathrm{pii}=\mathrm{S} 161886 \overline{6} 708000034 \&_{-}$check $=\mathrm{y} \varepsilon_{-}$origi $\mathrm{n}=$ articles_zone $=$ toolbar $\bar{\varepsilon}$ _coverDate $=15$ - May$2008 \& v i e w=c \&$ riginContentFamily $=$ serial $\&$ wchp $=d G L z V I S-$ zSkWb\&md5=dd10281b71780f66e5c67e674a2fa23d/1-s2.0S1618866708000034-main.pdf>. Acesso em: 28 abr. 2010.

JORGENSEN, B. S.; STEDMAN, R. C. A comparative analysis of predictors of sense of place dimensions: Attachment to, dependence on, and identification with lakeshore properties. Journal of Environmental Management, Philadelphia,v. 79, n. 3, p. 316-327, maio 2006. Disponível em: <http://www.wsl.ch/info/mitarbeitende/hunziker/teaching/download_ mat/Jorgenson_Stedman_2006.pdf>. Acesso em: 23 set. 2009. JUSTO, J. S.; VASCONCELOS, M. S. Pensando a fotografia na pesquisa qualitativa em psicologia. Estudos e Pesquisas em Psicologia, Rio de Janeiro, v. 9, n. 3, p. 760-774, 2009. Disponível em: <http://www.revispsi.uerj.br/v9n3/artigos/pdf/v9n3a13. pdf>. Acesso em: 31 mai. 2010. 
KAPLAN, R. The nature of the view from home: Psychological benefits. Environment and Behavior, Thousand Oaks, CA, v. 33, n. 4, p. 507-542, julho 2001. Disponível em: <http://eab.sagepub.com/content/33/4/507.abstract>. Acesso em: 28 abr. 2010.

KAPLAN, S. The restorative benefits of nature: Toward an integrative framework. J ournal of Environmental Psychology, Philadelphia, v. 15, n. 3, p. 169-182, setembro 1995. Disponível em: <http://www.uns. ethz.ch/edu/teach/masters/ebcdm/readings/Kaplan S.pdf>. Acesso em: 28 abr. 2010.

LOIZOS, P. Vídeo, filme e fotografias como documentos de pesquisa. In: BAUER, M. W.; GASKELL, G. (Orgs.). Pesquisa qualitativa com texto, imagem e som. Petrópolis: Vozes, 2002, p. 137-155.

MAURENTE, V.; TITTONI, J. I magens como estratégia metodológica em pesquisa: A fotocomposição e outros caminhos possíveis. Psicologia e Sociedade, Belo Horizonte, v. 19, n. 3, p. 33-38, setembro/dezembro 2007.2 Disponível em: <http://www.lume. ufrgs.br/bitstream/handle/10183/20555/0006335 36. pdf?sequence $=1>$. Acesso em: 26 mar. 2010.

NEIVA-SILVA, L.; KOLLER, S. H. O uso da fotografia na pesquisa em Psicologia. Estudos de Psicologia, Natal, v. 7, n. 2, p. 237-250, $2002 . \quad$ Disponível em: <http://www.scielo.br/pdf/epsic/v7n2/a05v07n2.pdf>. Acesso em: 26 mar. 2010.

PROSHANSKY, H. M. ; FABIAN, A. K. ; KAMINOFF, R. Place-identity: Physical world socialization of the self. J ournal of Environmental Psychology, Philadelphia, v. 3, n. 1, p. 57-83, março/setembro $1983 . \quad$ Disponível em: <http://www.sciencedirect.com/science/article/ pii/S02724944838002 18>. Acesso em: 24 jun. 2011.

RYAN, R. L. Exploring the effects of environmental experience on attachment to urban natural areas. Environment and Behavior, Thousand Oaks, CA, v. 37, n. 1, p. 3-42, 2005. Disponível em: <http://eab.sagepub.com/content/37/1/3.abstract>. Acesso em: 24 set. 2009.

SOMMER, R. O desenvolvimento e a aplicação dos conceitos de espaço pessoal. In: RIO, V. D.; DUARTE, C. R.; RHEINGANTZ, P. A. (Orgs.). Projeto do lugar: colaboração entre psicologia, arquitetura e urbanismo. Rio de Janeiro: Contra Capa/PROARQ, 2002, p. 19-29. SPELLER, G. M. A importância da vinculação ao lugar. In: SOCZKA, L. (Org.). Contextos humanos e psicologia ambiental. Lisboa: Fundação Calouste Gulbenkian, 2005, p.133-167.

TYGART, C. Public school vandalism: Toward a synthesis of theories and transition to paradigm analysis. Adolescence, Philadelphia, v. XXIII, n. 89, p. 187-200, 1988. Disponível em: 
<http://www. popcenter.org/problems/vandalism/PDFs/Tygart_1988. pdf>. Acesso em: 28 out. 2010.

VAN DEN BERG, A. E.; HARTIG, T.; STAATS, H. Preference for nature in urbanized societies: Stress, restoration, and the pursuit of sustainability. J ournal of Social I ssues, Washington, v. 63, n. 1, p. 79-96, $2007 . \quad$ Disponível em: <http://www.scoutinggelderland.nl/downloads/Debatreeks/Natuur/St ress,_natuur_en_de_stad_Berg_e.a._2007.pdf>. Acesso em: 28 abr. 2010.

VELARDE, M. D.; FRY, G.; TVEIT, M. Health effects of viewing landscapes: Landscape types in environmental psychology. Urban Forestry \& Urban Greening, Philadelphia, v. 6, n. 4, p. 199-212, 2007. <http://www.friskinaturen.org/media/landscape_viewing_2__bs.pdf> . Acesso em: 28 abr. 2010.

WALKER, A. J.; RYAN, R. L. Place attachment and landscape preservation in rural New England: A Maine case study. Landscape and Urban Planning, Philadelphia, v. 86, n. 2, p. 141-152, maio 2008.

<http://www.sciencedirect.com/science/article/pii/S01692046080003 15>. Acesso em: 23 set. 2009.

ZWEIG, A.; DUCEY M. H. A paradigmatic field: a review of research on school vandalism. Hackensack, NJ, National Council on Crime and Delinquency, 1978.

\section{Endereço para correspondência \\ Maíra Longhinotti Felippe}

Università degli Studi di Ferrara, Dipartimento di Architettura, Via Quartieri, 8, CAP 44100, Ferrara - FE, Italia.

Endereço eletrônico: Ingmra@unife.it, mairafelippe@gmail.com

\section{Luana dos Santos Raymundo}

Universidade Federal de Santa Catarina, Campus Universitário, Trindade, CEP 88040-900, Florianópolis - SC, Brasil.

Endereço eletrônico: lua_sr@yahoo.com.br

\section{Ariane Kuhnen}

Universidade Federal de Santa Catarina, Campus Universitário, Trindade, CEP 88040-900, Florianópolis - SC, Brasil.

Endereço eletrônico: ariane@cfh.ufsc.br

Recebido em: 27/03/2012

Aceito para publicação em: 14/10/2013

Acompanhamento do processo editorial: Deise Mancebo

\section{Notas}

* Arquiteta e Urbanista, e Mestre em Psicologia pela Universidade Federal de Santa Catarina, Florianópolis, Brasil. Doutoranda em Tecnologia da Arquitetura na Università degli Studi di Ferrara, Ferrara, Itália.

** Psicóloga, Mestre e doutoranda pelo Programa de Pós-Graduação em Psicologia da Universidade Federal de Santa Catarina, Florianópolis, Brasil. Laboratório de Psicologia Ambiental - LAPAM. 
*** Psicóloga, Mestre em Sociologia Política e Doutora em Ciências Humanas, Professora do Departamento de Psicologia e do Programa de Pós-Graduação em Psicologia da Universidade Federal de Santa Catarina, onde coordena o Laboratório de Psicologia Ambiental - LAPAM.

${ }^{1}$ Sabe-se que o uso de fotografias em pesquisas psicológicas, por exemplo, data da última década do século XIX (NEIVA-SILVA; KOLLER, 2002), período que coincide com o próprio reconhecimento da Psicologia como disciplina científica.

2 Projeto de pesquisa aprovado sob o número 561, em 14 de dezembro de 2009, pelo Comitê de Ética em Pesquisa com Seres Humanos da Universidade Federal de Santa Catarina (CEPSH - UFSC).

${ }^{3} \mathrm{O}$ juiz foi um psicólogo, do sexo feminino, com 32 anos.

${ }^{4}$ Ver Tabela 1 e Figura 3 para identificação e localização dos setores indicados; os códigos SAL e SAV referem-se a salas de aula e salas de vídeo de modo genérico, sem localização específica.

${ }^{5}$ Ver Tabela 1 e Figura 3 para identificação e localização dos setores indicados. Os códigos SAL, LAB e SAV referem-se a salas de aula, laboratórios e salas de vídeo de modo genérico, sem localização específica; o código EDA refere-se à Escola de Aplicação, destinada aos alunos dos primeiros anos do Ensino Fundamental.

${ }^{6}$ A abreviação D.C. refere-se à expressão depoimento coletado, a qual se segue a data do registro, o sexo do respondente ( $F$ para feminino e $M$ para masculino) e a sua idade no momento do depoimento. 